\title{
PENGGUNAAN SERAT SABUT KELAPA UNTUK PENGOLAHAN LIMBAH CAIR DOMESTIK
}

\author{
Hajimi $^{1}$, Salbiah ${ }^{1}$, Susilawati ${ }^{1}$ \\ ${ }^{1}$ Politeknik Kesehatan Kemenkes Pontianak Jurusan Kesehatan Lingkungan \\ Jl. 28 Oktober Kelurahan Siantan Hulu Kecamatan Pontianak Utara 78241 Kota Pontianak \\ E-mail : hajimis@yahoo.co.id
}

\begin{abstract}
Use of Coconut Fiber for Domestic Liquid Waste Processing. The oil and fat content in domestic wastewater is an element that can cause pollution of water bodies and inhibits the continued process in the Waste Water Treatment Plant. For this reason, efforts should be made to eliminate the womb in wastewater by filtration. In this study the filtration process uses a laboratory scale that is making a waste water solution from a mixture of water with various types of cooking spices that are fried using cooking oil and butter. The purpose of the study was to analyze the effectiveness of coconut fiber as a filter for waste oil (fat) in domestic wastewater. The research starts from the process of making coconut fiber and filtration tanks until it continues to the filtration treatment process. The results showed there were significant differences in oil (fat) levels in domestic wastewater between before and after filtration using coconut coir fiber media with a thickness of $20 \mathrm{~cm}, 40 \mathrm{~cm}$ and $60 \mathrm{~cm}$, which obtained the value of $\mathrm{p}(\mathrm{p}$-value $) \leq$ value $\alpha(0,05)$, i.e. $0.019,0.02$ and 0.006 . There is no significant difference in effectiveness between variations in thickness of coconut coir fibers as a filtration media against decreasing levels of oil (fat) in domestic wastewater, where a p-value of $0.073>\alpha(0.05)$ is obtained. The effectiveness of each reduction is 89.24 (thickness $20 \mathrm{~cm}$ ), 0.02 (thickness $40 \mathrm{~cm}$ ) and 0.006 (thickness $60 \mathrm{~cm}$ ). Coconut fiber is effective as a filtration media for treating domestic wastewater that contains oil (fat). It is recommended to conduct further research by increasing the residence time of wastewater in the filtration bath.
\end{abstract}

\section{Keywords: Filter; Filtration; Coconut Fiber; Domestic Waste Water; Oil/Fat.}

\begin{abstract}
Abstrak: Penggunaan Serat Kelapa untuk Pengolahan Limbah Cair Domestik. Kandungan minyak dan lemak dalam limbah cair domestik merupakan unsur yang dapat menyebabkan pencemaran badan air dan menghambat proses lanjutan dalam Instalasi Pengolahan Air Limbah. Untuk itu perlu dilakukan upaya menghilangkan kandungannya dalam air limbah yaitu dengan melakukan filtrasi. Pada penelitian ini proses filtrasi menggunakan skala laboratorium yaitu membuat larutan air limbah dari campuran air dengan berbagai jenis bumbu masak yang digoreng menggunakan minyak goreng dan mentega. Tujuan penelitian menganalisis efektifitas serat sabut kelapa sebagai filter limbah minyak (lemak) dalam air limbah domestik. Penelitian dimulai dari proses pembuatan serat sabut kelapa dan bak filtrasi sampai dilanjutkan ke proses perlakuan filtrasi. Hasil Penelitian menunjukkan ada perbedaan signifikan kadar minyak (lemak) dalam air limbah domestik antara sebelum dengan sesudah filtrasi menggunakan media serat sabut kelapa dengan ketebalan $20 \mathrm{~cm}, 40 \mathrm{~cm}$ dan $60 \mathrm{~cm}$, dimana diperoleh nilai $\mathrm{p}$ ( $p$-value $) \leq$ nilai $\alpha(0,05)$, yaitu $0,019,0,02$ dan 0,006 . Tidak ada perbedaan efektivitas yang signifikan antara variasi ketebalan serat sabut kelapa sebagai media filtrasi terhadap penurunan kadar minyak (lemak) dalam air limbah domestik, dimana diperoleh nilai p ( $p$-value) $0,073>$ nilai $\alpha(0,05)$. Adapun efektivitas penurunannya masingmasing adalah 89,24 (ketebalan $20 \mathrm{~cm}$ ), 0,02 (ketebalan $40 \mathrm{~cm}$ ) dan 0,006 (ketebalan $60 \mathrm{~cm}$ ). Serat sabut kelapa efektif sebagai media filtrasi untuk mengolah air limbah domestik yang mengandung minyak (lemak). Disarankan untuk melakukan penelitian lanjutan dengan menambah waktu tinggal air limbah dalam bak filtrasi.
\end{abstract}

Kata Kunci: Filter; Filtrasi; Sabut Kelapa; Air Limbah Domestik; Minyak/Lemak.

\section{PENDAHULUAN}

Air merupakan senyawa kimia yang paling berlimpah di alam, namun demikian sejalan dengan meningkatnya taraf hidup manusia, maka kebutuhan air 
pun meningkat pula, sehingga akhir-akhir ini air menjadi barang yang "mahal" (1).

Air merupakan salah satu unsur terpenting yang dibutuhkan oleh semua makhluk hidup terutama manusia. Djoko Pekik Irianto (2006: 11) menyatakan " Air merupakan komponen terbesar dari struktur tubuh manusia kurang lebih 60 $70 \%$ berat badan orang dewasa berupa air sehingga sangat diperlukan air minum oleh tubuh terutama bagi yang berolahraga atau kegiatan berat yaitu air mineral". Menurut Mary E. Beck (2000: 46) menyatakan " air menjadi bagian kurang lebih 60 hingga 70 persen dari berat total tubuh. Menurut Asmadi dkk (2011: 7), tubuh manusia membutuhkan air untuk dikonsumsi sebanyak 2,5 liter atau setara dengan delapan gelas setiap harinya (2).

Saat ini banyak aktifitas manusia yang menyebabkan terjadinya pencemaran air, baik aktifitas rumah tangga maupun industri. Pencemaran yang mengakibatkan penurunan kualitas air dapat berasal dari limbah terpusat (point sources) seperti : limbah industri, limbah usaha perternakan, perhotelan, rumah sakit dan limbah tersebar ( non point sources) seperti : limbah pertanian, perkebunan dan domestic (3).

Air Limbah domestik terdiri dari limbah rumah tangga, perkantoran, pasar dan pusat perdagangan. Salah satu unsur dari limbah cair domestik yang menjadi penyebab tercemarnya lingkungan adalah unsur minyak. Minyak dan lemak merupakan komponen utama bahan makanan yang juga banyak didapat di dalam air limbah. Minyak dan lemak membentuk ester dan alkohol. Lemak tergolong pada bahan organik yang tetap dan tidak mudah untuk diuraikan oleh bakteri. Terbentuknya emulsi air dalam minyak akan membuat lapisan yang menutupi permukaan air dan dapat merugikan, karena penetrasi sinar matahari ke dalam air berkurang serta lapisan minyak menghambat pengambilan oksigen dari udara menurun. Untuk air sungai kadar maksimum minyak dan lemak $1 \mathrm{mg} / \mathrm{l}$. Sedangkan menurut Peraturan Menteri Lingkungan Hidup dan Kehutanan Nomor P.68/Menlhk-
Setjen/2016 tentang Baku Mutu Air Limbah Domestik kadar maksimal minyak dan lemak yaitu $5 \mathrm{Mg} / \mathrm{l}$ (4).

Berdasarkan data di atas, maka perlu dilakukan suatu penelitian yang dapat menghilangkan kandungan minyak (lemak) di dalam air limbah. Cara atau metode yang sering digunakan untuk mengolah atau menyisihkan minyak dan lemak adalah dengan menggunakan proses adsropsi. Adsorpsi adalah proses fisika dan atau kimia dimana substansi terkumulasi atau terkumpul pada lapisan permukaan adsorben. Banyak jenis adsorben yang bisa digunakan diantaranya adalah karbon aktif, debu terbang (fly ash), rumput/lumut, serbuk kayu, kayu, debu kasar, ampas tebu, kulit jagung dan bahan berserat lainnya. Sabut kelapa dapat menjadi pilihan untuk digunakan sebagai adsorben karena sabut kelapa mengandung serat yang cukup tinggi. Sabut kelapa terdiri dari serat dan gabus yang menghubungkan satu serat dengan serat lainnya. Kemudian dibersihkan dengan memisahkan serat dari serabutnya. Setiap butir kelapa mengandung $25 \%$ serat. Sedangkan sabut kelapa merupakan bagian yang cukup besar dari buah kelapa, yaitu 35\% dari berat keseluruhan buah. Pembersihan serat dari gabus perlu dilakukan, karena gabus memiliki sifat mekanis yang rendah (mudah putus) dan memiliki daya serap air yang tinggi (5).

Hasil penelitian yang peneliti lakukan tahun 2018 tentang efektifitas serat sabut kelapa sebagai media filtrasi limbah minyak (lemak) menggunakan 3 variasi ketebalan dengan waktu tinggal selama 60 menit diperoleh hasil yaitu ketebalan $20 \mathrm{~cm}$ bisa menurunkan kadar minyak (lemak) sampai 89,24\%, ketebalan $40 \mathrm{~cm}(95,03 \%)$, dan ketebalan $60 \mathrm{~cm}$ (95,89\%). Penelitian tersebut dilakukan dengan skala laboratorium. Waktu tinggal (Retention Time) air limbah penting untuk diperhitungkan karena sangat terkait dengan dimensi ukuran bak yang diperlukan untuk dibuat. Selain itu masalah keterbatasan lahan menjadi faktor yang penting untuk diperhatikan terkait dengan ukuran bak yang akan dibuat. Berdasarkan masalah di atas maka 
peneliti tertarik untuk mengetahui tentang "Penggunaan Serat Sabut Kelapa Untuk Pengolahan Limbah Cair Domestik di Kota Pontianak"

\section{BAHAN DAN CARA PENELITIAN}

\section{Tempat dan Waktu Penelitian}

Penelitian ini dilaksanakan di Komplek Pasar Dahlia Jl. H. Rais A. Rahman Kelurahan Sungai Jawi Dalam
Kecamatan Pontianak Barat Kota Pontianak, mulai Juni sampai dengan September 2019.

Tabel.1 Alat dan Bahan yang Digunakan dalam Penelitian

\begin{tabular}{llll}
\hline \multicolumn{1}{c}{ Alat } & \multicolumn{1}{c}{ Bahan } \\
\hline - & Bak Filtrasi & - & Serat Sabut Kelapa \\
- & Ember Uk. 20 Liter & - & Air Sumur \\
- Baskom Plastik Uk. 30 Liter & - & Minyak Goren \\
- Kayu Pengaduk & - & Mentega \\
- & Centong & - & Campuran Bumbu / rempah masakan \\
\hline
\end{tabular}

Sumber : Data primer hasil penelitian

\section{Prosedur Kerja atau Tahapan Penelitian}

Proses pelaksanaan penelitian dilakukan dengan memberikan perlakuan seperti yang sebenarnya terjadi dalam proses pencucian di rumah tangga atau di rumah makan (warung nasi). Proses pengambilan sampel dilakukan mulai dari sampel sebelum masuk ke alat filtrasi (Pre) sampai setelah proses filtrasi (Post) secara berurutan mulai 30 menit, 60 menit, 120 menit sampai 360 menit, proses ini dilakukan sebanyak enam (6) kali pengulangan. Adapun tahapan proses pelaksanaan penelitian ini adalah sebagai berikut :

a. Membuat larutan minyak (lemak) untuk proses perlakuan. Untuk pengulangan 1, 2 dan 3 masingmasing dibuat larutan campuran antara 100 gr mentega di tambah dengan $100 \mathrm{ml}$ minyak goreng curah dan 250 gr campuran berbagai macam bumbu mentah. Pengulangan 4,5 dan 6 masingmasing dibuat larutan campuran antara $200 \mathrm{gr}$ mentega ditambah dengan $200 \mathrm{ml}$ minyak goreng curah dan 500 gr campuran berbagai macam bumbu mentah.

\section{Alat dan Bahan}

Alat dan bahan yang digunakan dalam penelitian ini lebih jelasnya dapat dilihat pada tabel.1 
sampai penuh (sampel setelah perlakuan)

h. Lakukan proses ini sesuai lama waktu yang ditentukan yaitu 30 menit, 60 menit, 120 menit dan 360 menit.

i. Simpan sampel di dalam lemari pendingin di laboratorium terpadu Poltekkes Kemenkes Pontianak

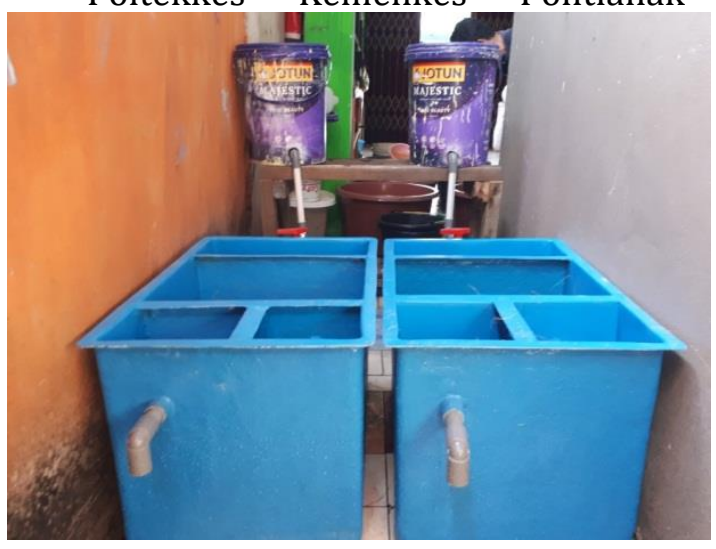

sebelum dikirim ke laboratorium PT. Sucofindo untuk diperiksa.

j. Lakukan prosedur yang sama untuk semua proses pengambilan sampel

k. Kirim sampel ke Laboratorium PT. Sucofindo untuk pemeriksaan parameter minyak (lemak)

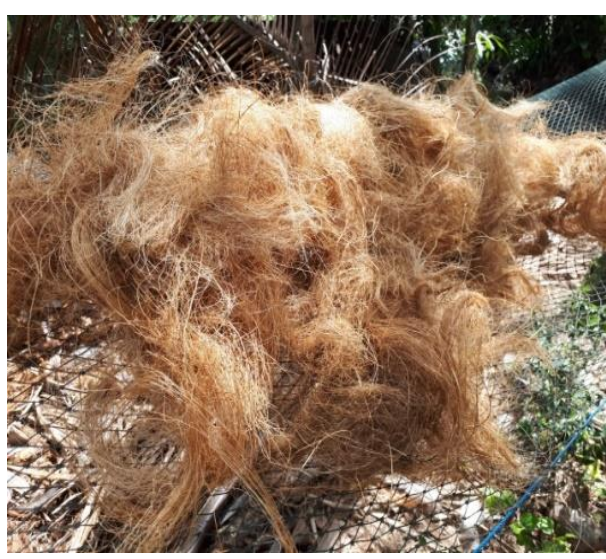

Gambar.1 Bak filtrasi dengan media serat sabut kelapa

Sumber : Data primer hasil penelitian

\section{HASIL DAN PEMBAHASAN}

Tahapan dari proses perlakuan dimulai dari larutan yang mengandung minyak (lemak) dimasukkan ke dalam ember, selanjutnya kran dibuka sesuai dengan debit yg sudah diatur untuk masing-masing lama waktu kontak. Selanjutnya larutan masuk ke dalam kotak pertama dari bak filtrasi melalui pipa inlet dan kontak langsung media serat sabut kelapa. Dari bak pertama melalui bagian bawah kota pertama larutan akan masuk ke bak kedua dan kembali kotak dengan media serat sabut kelapa dan akan keluar melalui pipa autlet pertama di bagian atas ke kotak ketiga dan kembali kotak dengan media serat sabut kelapa. Setelah melalui kotak ketiga, larutan akan masuk ke kotak empat melalui bagian bawah kota ketiga dan akan keluar melalui pipa outlet 2 (terakhir) dan air hasil olahan langsung diambil sebagai hasil akhir dari tahapan proses perlakuan. Hasil pengukuran kadar minyak (lemak) pada air limbah dilakukan sebelum dan sesudah filtrasi menggunakan media serat sabut kelapa ketebalan media $20 \mathrm{~cm}$ dengan tiga (3) variasi lama waktu kontak yaitu 30 menit, 60 menit, dan 120 dapat dilihat pada tabel.2 di bawah ini :

Tabel.2 Hasil Pengukuran Kadar Minyak (Lemak) Menggunakan Filtrasi Media Serat Sabut Kelapa Ketebalan $20 \mathrm{~cm}$ Berdasarkan lama waktu kontak

\begin{tabular}{|c|c|c|c|c|}
\hline \multirow{3}{*}{$\begin{array}{c}\text { Variasi Lama } \\
\text { Waktu Kontak }\end{array}$} & \multicolumn{4}{|c|}{ Rata-rata Hasil Pengukuran Kadar Minyak (Lemak) } \\
\hline & \multirow{2}{*}{$\begin{array}{c}\text { Sebelum } \\
\mathrm{mg} / \mathrm{l}\end{array}$} & \multirow{2}{*}{$\begin{array}{c}\text { Sesudah } \\
\text { mg/l }\end{array}$} & \multicolumn{2}{|c|}{ \% Penurunan } \\
\hline & & & $\mathbf{m g} / \mathbf{l}$ & $\mathbf{m g} / \mathbf{l}$ \\
\hline 30 Menit & 595.13 & 131.87 & 463.27 & 65.67 \\
\hline 60 Menit & 595.13 & 208.45 & 386.68 & 56.31 \\
\hline 120 Menit & 595.13 & 1212.67 & -617.53 & -78.90 \\
\hline 360 Menit & 595.13 & 1599.23 & -1004.10 & -175.70 \\
\hline
\end{tabular}

Sumber : Data primer hasil penelitian 
Hasil uji statistik menggunakan Paired Sample T-Test menunjukkan hasil tidak ada perbedaan yang signifikan dimana diperoleh nilai $\mathrm{p}$ ( $p$-value $>0,05)$, sedangkan hasil uji Anova diperoleh nilai $\mathrm{p}$ (p-value) 0,000 artinya ada perbedaan yang signifikan kandungan minyak (lemak) pada air limbah yang difiltrasi menggunakan media serat sabut kelapa ketebalan $20 \mathrm{~cm}$, antara variasi waktu kontak yang digunakan. Semakin tebal media serat sabut kelapa yang digunakan sebagai media filtrasi akan semakin efektif untuk menyaring minyak atau lemak. Hal ini karena media serat sabut kelapa mengandung bahan semisellulossa. Kuadrat (2001) menyatakan bahwa bahan yang mempunyai komponen sellulosa dan lignin memiliki daya serap 6000 kali lebih besar dari pada daya serap karbon aktif (6). Selain itu lama waktu kontak antar air limbah dengan bahan absorben (serat sabut kelapa) juga berpengaruh terhadap penurunan kandungan minyak (lemak) dalam air limbah. Menurut Wijaya et al. (2002), waktu kontak merupakan suatu hal yang sangat menentukan dalam proses adsorbsi. Waktu kontak yang lebih lama memungkinkan proses difusi dan penempelan molekul adsorbat berlangsung lebih baik. Konsentrasi zat-

\section{KESIMPULAN DAN SARAN}

Berdasarkan hasil penelitian yang dilakukan, maka dapat disimpulkan bahwa serat sabut kelapa dapat digunakan sebagai media filtrasi untuk mengurangi kandungan minyak (lemak) dalam air limbah domestik, walaupun persentase penurunannya baru mencapai angka 65\%. Agar persentase penurunannya maksimal maka sebaiknya penelitian dilakukan langsung di tempat atau lokasi yang menghasilkan limbah minyak (lemak) seperti restoran atau rumah makan. Selain itu penelitian harus dibedakan alat dan prosesnya untuk masing-masing perlakuan waktu kontak atau waktu tinggal limbah dalam bak filtrasi.

\section{KEPUSTAKAAN}

zat organik akan turun apabila waktu kontaknya cukup (7).

Ada beberapa faktor lain yang dapat menyebabkan hasil seperti di atas yaitu : (1) Konsentrasi minyak (lemak) yang berbeda pada saat dimasukkan dalam alat filtrasi pada setiap tahap perlakuan sehingga dapat menyebabkan terjadinya penumpukan atau peningkatan konsentrasi dan volume minyak (lemak) dalam sampel. (2) Terjadinya proses jenuh (kejenuhan) pada media filter sehingga unsur minyak (lemak) yang menempel atau tertangkap oleh media serat sabut kelapa semakin sedikit sehingga semakin lama jumlahnya semakin meningkat di dalam sampel. Hal ini sesuai dengan teori absorbsi yaitu suatu proses dimana suatu partikel terperangkap ke dalam struktur suatu media dan seolah-olah menjadi bagian dari keseluruhan media tersebut. Proses ini dijumpai terutama dalam media karbon aktif. Karbon aktif memiliki ruang pori sangat banyak dengan ukuran tertentu. Pori-pori ini dapat menangkap partikel-partikel sangat halus (molekul) dan menjebaknya disana. Dengan berjalannya waktu pori-pori ini pada akhirnya akan jenuh dengan partikelpartikel sangat halus sehingga tidak akan berfungsi lagi (8).

1. Susana T. Air Sebagai Sumber Kehidupan. Oseana [Internet]. 2003;XXVIII(3):17-25. Available from: www.oseanografi.lipi.go.id

2. Sari IPTP. Tingkat Pengetahuan Tentang Pentingnya Mengkonsumsi Air Mineral Pada Siswa Kelas IV Di Sd Negeri Keputran a Yogyakarta. J Pendidik Jasm Indones. 2014;10(November):55-61.

3. Asmadi. Dasar-Dasar Teknologi Pengolahan Air Limbah. Yogyakarta: Goysen Publishing; 2012.

4. Pemerintah Kota Surabaya Dinas Lingkungan Hidup. Pengelolaan Air Limbah Kegiatan Bengkel. Surabaya; 2019. 15 p.

5. Dan G, Liat T. Papan Dengan Berbagai Jenis Matrik:

6. Herman AM. Pengelolaan Limbah Padat 
Sabut Kelapa Sawit Sebagai Bahan Untuk Mengelola Limbah Cair. Iltek. 2012;6(12).

7. Zaharah TA, Moelyani RRE. Reduksi minyak, lemak, dan bahan organik limbah rumah makan menggunakan grease trap termodifikasi karbon aktif. J Pengelolaan Lingkung Berkelanjutan. 2017;1(3):25-32.

8. Suharto I. No Title [Internet]. Yogyakarta: Andi; 2011. xxii, 518 hlm.; $23 \mathrm{~cm}$. Available from: http://libcat.uinmalang.ac.id//index.php?p=show_detai $1 \&$ id $=44909$ 
